\title{
Advanced paternal age as a risk factor for autism spectrum disorder in a Mexican population
}

\author{
Jessica Fajardo, 1,2 Lilia Albores-Gallo, ,,4 Alma Delia Genis-Mendoza, 1,4 \\ José Jaime Martínez-Magaña,' Humberto Nicolini'
}

Laboratorio de Genómica de Enfermedades Psiquiátricas y Neurodegenerativas, Instituto Nacional de Medicina Genómica, Ciudad de México, México

2 Facultad de Medicina, Universidad Nacional Autonóma de México, Ciudad de México, México.

3 Departamento de Epidemiología, Asociación Mexicana de Niños con TDAH y Trastornos Asociados A.C., Ciudad de México, México.

${ }^{4}$ Hospital Psiquiátrico Infantil Juan N. Navarro, Servicios de Atención Psiquiátrica, Ciudad de México, México.

Correspondence:

Humberto Nicolin

Instituto Nacional de Medicina Genómica.

Periférico Sur 4809, Arenal Tepepan,

14610 Tlalpan, Ciudad de México,

México.

Phone: 5350 - 1900, Ext. 1196

Email: hnicolini@inmegen.gob.mx

Received: 22 July 2019

Accepted: 30 January 2020

\section{Citation:}

Fajardo, J., Albores-Gallo, L., Genis-Mendoza, A. D., MartínezMagaña, J. J., \& Nicolini, H. (2020). Advanced paternal age as a risk factor for autism spectrum disorder in a Mexican population. Salud Mental, $43(3), 113-118$

DOI: $10.17711 /$ SM. $0185-3325.2020 .016$

\begin{abstract}
Introduction. Risk factors for autism spectrum disorders (ASD) have been identified, as is the case of advanced parental age. Advanced parental age as an ASD risk factor has been studied in Scandinavian populations; there are no reports for Mexican children. Objective. The present work aim is to analyze if advanced parental age is a risk factor for ASD in a Mexican children sample. Method. Mexican children $(N=1068)$ participated in a case-control study, 162 had an ASD diagnosis. Multivariate logistic regression adjusted by cofounders was performed to explore the effect of paternal age on ASD risk. Results. Advanced paternal age in Mexican children increases the risk for ASD, and also, a difference of 10 years between parental ages have a higher risk. Discussion and conclusion. The effect of advanced paternal age in Mexican children was lower than those reported previously for other populations. Advanced paternal age and difference between parental ages could be a risk factor for ASD in Mexican population. Nevertheless, the analysis of larger sample sizes is required.
\end{abstract}

Keywords: Risk factors, maternal age, paternal age, autism spectrum disorder, Mexican population.

\section{RESUMEN}

Introducción. Se han identificado algunos factores de riesgo para el trastorno del espectro autista (TEA) como es el caso de la edad parental avanzada. La edad parental avanzada es un factor de riesgo que ha sido muy explorado en poblaciones escandinavas; sin embargo, no existen reportes en niños de ascendencia mexicana. Objetivo. El presente trabajo tiene el objetivo de analizar si la edad parental avanzada es un factor de riesgo para TEA en una muestra de niños mexicanos. Método. Un total de 1068 niños de la Ciudad de México se incluyeron en un estudio de casos-controles, de los cuáles 162 contaban con diagnóstico de TEA. Regresiones logísticas multivariable, ajustadas por confusores, se realizaron para explorar el efecto de la edad parental avanzada en el riesgo para TEA. Resultados. La edad paterna avanzada en niños mexicanos aumentó el riesgo para TEA; también, una diferencia de edad de 10 años entre los padres presenta un mayor riesgo. Discusión y conclusión. El efecto de la edad paterna avanzada en los niños mexicanos fue mucho más bajo que aquella reportada para otras poblaciones. La edad paterna avanzada y la diferencia entre la edad parental puede ser un factor de riesgo para TEA en población mexicana. Sin embargo, se requieren análisis en poblaciones con mayor tamaño de muestra.

Palabras clave: Factores de riesgo, edad materna, edad paterna, trastorno del espectro autista, población mexicana. 


\section{INTRODUCTION}

Autism spectrum disorder (ASD) affects approximately 7.6 per 1000 children worldwide (Baxter et al., 2015; Elsabbagh et al., 2012; Fombonne et al., 2016; Siu et al., 2016). The core symptoms of ASD are deficits in social communication and restricted interests and stereotyped and repetitive moments (Christiansz, Gray, Taffe, \& Tonge, 2016; Kent et al., 2013; Lee, Thomas, \& Lee, 2015). Despite advances in the investigation of ASD, there is still no clear evidence concerning the etiology of these disorders (Muhle, Reed, Stratigos, \& Veenstra-VanderWeele, 2018). Some risk factors for ASD have attracted considerable attention, like advanced paternal age (APA) (Croen, Najjar, Fireman, \& Grether, 2007; Glasson et al., 2004; Larsson et al., 2005; Lauritsen, Pedersen, \& Mortensen, 2005; Maimburg \& Vaeth, 2006; Reichenberg, Gross, Sandin, \& Susser, 2010). Advanced paternal age is known as a risk factor for ASD (Bilder, Pinborough-Zimmerman, Miller, \& McMahon, 2009; Buizer-Voskamp et al., 2011; Burstyn, Sithole, \& Zwaigenbaum, 2010; D’Onofrio et al., 2014; Durkin et al., 2008; Frans et al., 2013; Golding, Steer, \& Pembrey, 2010; Grether, Anderson, Croen, Smith, \& Windham, 2009; Hultman, Sandin, Levine, Lichtenstein, \& Reichenberg, 2011; Idring et al., 2014; Lampi et al., 2013; Lundstrom et al., 2010; Mamidala et al., 2013; Parner et al., 2012; Pinborough-Zimmerman et al., 2011; Sasanfar et al., 2010; Shelton, Tancredi, \& Hertz-Picciotto, 2010; Sun, Allison, Auyeung, Baron-Cohen, \& Brayne, 2014; van Balkom et al., 2012; Williams, Helmer, Duncan, Peat, \& Mellis, 2008; Wu et al., 2017; Zhang et al., 2010). Nevertheless, the biological mechanism underlying this association remains unknown. Meanwhile, some hypotheses have been established to explore the molecular mechanism underlying the association of advanced paternal age and ASD. These hypotheses may be divided in two (but they would not be mutually exclusive): one that involves sequence changes in the DNA (de novo mutations) and the other that does not involve this DNA sequence changes (epigenetic changes) (de Kluiver, Buizer-Voskamp, Dolan, \& Boomsma, 2017; Janecka et al., 2017). Supporting the hypothesis of sequence DNA changes in APA, it has been proposed that whilst male age increases, the rate of genetic mutations during spermatogenesis also increases, affecting the probability of inheriting de novo mutations to the off-spring which could contribute to an increased morbidity (Buwe, Guttenbach, \& Schmid, 2005; Crow, 2000; Flatscher-Bader et al., 2011; Kong et al., 2012; Sanders et al., 2011; Szatmari et al., 2007). In the case of the epigenetic alterations hypothesis (no DNA sequence alterations), establishes that aging affects the chromatin structure and DNA methylated patterns of sexual cells, which could lead to inherited gene expression alterations in the newly formed zygote derivate from altered aging-related epigenetic changes (Jenkins, Aston, Pflueger, Cairns, \& Carrell, 2014; Kimura, Yoshizaki, \& Osumi, 2018). Contrasting this hypothesis of aging-related changes, in some analysis it has been reported that the difference between the conceptional parental age is a risk factor for ASD, principally by younger mothers (Sandin et al., 2016). Where this difference has to be explored in other populations.

However, most studies are centered in Scandinavian or Asian populations, leaving behind other populations, like, Latin Americans and African Americans. Most research includes children living outside their countries of birth (principally in the United States) and the possible effects of this risk factor in the individuals from these populations residing in their countries of birth, is scarce (Becerra et al., 2014). A recent meta-analysis of APA and ASD, screening almost 67000 individuals with ASD, concluded that APA is an ASD-risk factor influenced possibly by the residing country (Wu et al., 2017). In this study, Wu et al. reported that the effect of APA in North America is lower than the effect in children residing in Europe and is even lower than the effect of children residing in Asia. In the case of Mexican children, there are no studies analyzing the effect of APA as a risk factor for ASD. This study aims to perform an exploratory analysis of APA as a risk factor for ASD in children residing in Mexico City.

\section{METHOD}

\section{Design of the study}

The study design was a case-control, observational, cross-sectional, with a non-probabilistic, and consecutive sampling.

\section{Participants}

The total sample included ( $N=1068$ children). We considered children with ASD diagnosis $(n=162)$ as cases and neurotypical children (NT, $n=906)$ as controls.

\section{Procedure}

The structure of the sample evaluation was performed following the same criteria previously reported for a co-validation of an autism instrument (Albores-Gallo et al., 2012). Children with ASD (case group) were recruited from the outpatient psychiatric services of the Hospital Psiquiátrico Infantil Juan N. Navarro from March 2014 to November 2016. Neurotypical children (control group) were from a community-based sample recruited from nurseries located in four different districts of Mexico City. The four kindergartens belong to the DIF system and located in Tlalpan, which receives children from parents who have no social security. This characteristic makes this population very similar to the one that receives medical care in the Hospital Psiquiátrico Infantil. 
Male and female children, between 18 to 72 months of age were recruited. We excluded children with known comorbid severe chronic diseases, such as diabetes, cancer, or sensory impairments such as deafness, blindness, or a genetic syndrome associated with autism such as tuberous sclerosis, Rett syndrome, or fragile X. All children were screened for ASD with M-CHAT scale (Albores-Gallo et al., 2012). NT children were excluded if they failed more than two critical items or more than three items in the M-CHAT scale. In the case of children in the ASD group, all the children were evaluated by an expert child psychiatry and a senior board-certified child psychiatrist. The ASD diagnosis was based on DSM-IV criteria and confirmed by the ADI-R instrument (Lord, Rutter, \& Le Couteur, 1994). For this study, we analyzed the following variables: age of the parents at the moment of the birth of the child (conceptional age).

\section{Statistical analysis}

In all the manuscript, we will refer to the conceptional maternal or the conceptional paternal age as only paternal age or maternal age. To explore the normality distribution of the parental age, we used a Kolmogorov-Smirnov test. To compare the differences in parental age between ASD and NT groups, we performed a Wilcoxon test. We categorized the individuals based in the distribution of the overall parental age, based in intervals of 10 years. We used as reference for the next models, were the overall mean, median and mode of the parental age was found.

A series of multivariate logistic regression models were performed to estimate the odds ratios (OR) and 95\% confidence intervals ( $C I$ 95\%) to analyze the paternal age and maternal age as a risk factor for ASD. All the models were adjusted for the opposite parental age (i.e, if we analyzed the parental age, we fitted the models with maternal age as a covariate), age, and gender of the child (covariables). A $p$ less than .05 was considered statistically significant. We fitted three different independent models.

In the first model we measured the associations between the independent variable of maternal or paternal age (i.e., in two independent models, one for maternal age and one for paternal age) and the dependent variable, the ASD case status (all models adjusted by covariables).

In the second model, we also measured the association between the maternal or paternal age and the ASD case status, but in this analysis we categorized the individuals based in the conception maternal and paternal age. Five categories: lower than 20, 20 to 29, 30 to 39, 40 to 49, and higher than 50. In all the models, the $O R$ and $C I$ $95 \%$ was calculated, the category where the mean, median, and mode overall sample, parental age was used as the reference category.

Additionally, in the third model, we performed an analysis to search if parental age differences as a risk factor for
ASD. For this analysis, we calculated the difference of the paternal age subtracted from the maternal age (paternal age-maternal age) and coded as a continuous variable. Once we performed this parental age difference calculation we categorized the children in four categories: children with differences in parental age higher than 10 years (with higher maternal age); children with difference in parental ages $>$ zero and $<10$ (with higher maternal age); children without differences in parental age; children with difference in parental ages $>$ zero and $<10$ (with higher paternal age); and children with differences in parental age higher than 10 years (with higher paternal age). Again, multivariate logistic regressions were done to calculate $O R$ and $C I$ 95\%. We considered the group without difference between parental age as the reference group for these parameters calculations. All models were fitted using R (R Development Core Team, 2008).

\section{Ethical considerations}

The ethics and research committee approved the study of the Hospital Psiquiátrico Infantil Juan N. Navarro (approval number $=$ II $1 / 01 / 0304 / T c)$. To be included in the study, written informed consent and assent was obtained from each study participant through the primary caregiver of each infant.

\section{RESULTS}

The mean age of the children with ASD $(M=4.40 S D \pm$ 1.11) was slightly lower, but not statistically significant compared to the mean age of the children diagnosed with ASD $(M=4.48 S D \pm 1.13)$ (Table 1). The proportion of males/females in children diagnosed with ASD was higher than those children with NT, being this relationship of three boys to one girl in the children diagnosed with ASD.

Maternal age was slightly higher in mothers of children diagnosed with ASD $(M=27.60 S D \pm 5.85)$, but not statistically significant different from the maternal age of the

Table 1

Clinical and sociodemographic data of the participants

\begin{tabular}{lccccc}
\hline & $A S D(n=162)$ & $N T(n=906)$ \\
\hline Sex, $n(\%)^{\mathrm{a}}$ & & & & $p<.00^{\mathrm{c}}$ \\
$\quad$ Male & 123 & $(75.93)$ & 480 & $(52.98)$ & \\
Female & 39 & $(24.07)$ & 426 & $(47.02)$ & \\
Age, M $(S D)^{\mathrm{b}}$ & $4.40(1.11)$ & $4.48(1.13)$ & $p=.41$ \\
$\quad$ Maternal age & $27.60(5.85)$ & $26.73(5.97)$ & $p=.13$ \\
Paternal age & $31.54(8.67)$ & $29.17(8.67)$ & $p<.001$ \\
M-CHAT, M (SD) & $6.66(4.21)$ & $3.27(2.19)$ & $p<.0001$ \\
\hline
\end{tabular}

Notes: a For sex the total individuals $(n)$ and the percentage inside the parenthesis (\%) is reported. ${ }^{b}$ For age and M-CHAT the mean (M) and the standard deviation $(S D)$ inside the parenthesis is reported. ${ }^{c}$ For sex a $p$ value is reported for a chi-square test, meanwhile, for age and M-CHAT a Wilcoxon test $p$ value is reported. 
Table 2

Comparisons of parental age as an ASD risk in the stratified analysis

\begin{tabular}{|c|c|c|}
\hline Categories & Paternal age & Maternal age \\
\hline Lower than 20 years & $1.28[.61-2.54] p=.32^{\mathrm{C}}$ & $.34[.14, .69] p<.01$ \\
\hline 20 to 29 years $^{a}$ & $.65[.44-.98] p=.04^{d}$ & Reference \\
\hline 30 to 39 years $^{\text {b }}$ & Reference & $1.16[.78,1.71] p=.45$ \\
\hline 40 to 49 years & $2.57[1.47-4.49] p<.001$ & $1.14[.40,2.85] p=.79$ \\
\hline Higher than 50 years & $2.79[.53-12.53] p=.19$ & $N A^{e}$ \\
\hline
\end{tabular}

Notes: a The category where the overall mean, median and mode of the paternal age $(29.53,29$, 29 years) in the sample was used as reference for $O R$ and $C l 95 \%$ calculations $(\geq 30,<40)$. ${ }^{\circ}$ The category where the overall mean, median and mode of the paternal age $(26.86,26,25$ years) in the sample was used as reference for $O R$ and $C / 95 \%$ calculations $(\geq 20,<30)$. ${ }^{c}$ The reported values are OR $[\mathrm{Cl} / 95 \%] p .{ }^{d}$ In bold are the statistical significant results (values of $p$ less than .05). ${ }^{\circ}$ No children of the overall sample have a mother with maternal age higher or equal than 50 years.

mothers with NT children $(M=26.73 S D \pm 5.97, \mathrm{p}=.13)$. Meanwhile, paternal age was higher in children diagnosed with ASD $(M=31.54 S D \pm 8.67)$ compared to the paternal age of NT children $(M=29.17 S D \pm 8.67)$, being this difference statistically significant $(p<.001)$. In the first regression models, maternal age did not reach statistical significance as a risk factor for $\operatorname{ASD}(O R=1.02, C I 95 \%[.99,1.06], p=$ $.07)$. In contrast, paternal age increased risk for ASD $(O R=$ $1.04, C I 95 \%[1.02,1.07], p<.001)$. Also, in the stratified analysis (five categories of parental age), advanced paternal age increased the risk to ASD, exclusively when the age of the father was between 40 to 49 years $(O R=2.57, C I 95 \%$ $[1.47,4.49], p<.001$ ) (Table 2). Also, a reduced parental age, principally between 20 to 29 years, reduced the risk to ASD. In contrast, in this stratified analysis, the advanced maternal age did not increase the risk for ASD.

In the third model, the difference in parental age was tested as a risk factor for ASD. In this analysis, when the father had a higher age than the mother, the risk for ASD increased for a difference between 10 years $(O R=3.37$, CI 95\% [1.65, 7.21], $p=.001$ ) (Table 3). Also, when the mother had a higher age than the father, this results in a higher risk, but this model reaches only nominal statistical significance.

\section{DISCUSSION AND CONCLUSION}

In this study, we analyzed the advanced parental age as a risk for ASD in children residing in Mexico City. The re- sults showed a small increased risk for ASD when the father had an advanced parental age, and higher when the age difference between parents was larger than 10 years. However, the risk of APA in our sample (OR of 1.04) is lower compared to the result reported in a recent worldwide meta-analysis (OR of 1.41) (Wu et al., 2017). Comparing our preliminary estimate with each geographical area reported in the meta-analysis, this is almost the half of the one reported for Asia and Oceania (OR of 2.56), and lower than Europe (OR of 1.44). This estimate is even lower than the results reported for the North America geographical area (which has the lower risk effect of advanced paternal age in ASD, OR: 1.44). The studies included in this meta-analysis, located in North America, were only recruited in the United States, which is the principal country with migration from Mexico. In this sense, the effect of APA for ASD could be inferred to be the same for the Mexican population residing in Mexico or in the United States. However, epidemiological studies done with Hispanic population residing in the US (included Mexican) suggest that ethnicity might influence the prevalence of ASD. For example, mothers with Hispanic ancestry were less likely to have a child with ASD. Moreover, when the mother is an immigrant, the likelihood of having a child with ASD is reduced (Durkin et al., 2008; Liptak et al., 2008; Pedersen et al., 2012; Pinborough-Zimmerman et al., 2011; Schieve et al., 2012). This could mean that the effect of ASD risk factors in Hispanic residing individuals could be lower than the effects in individuals residing outside their country of birth; nevertheless, this lower probability of ASD remains to be explored in further studies. Anoth-

Table 3

Difference of parental ages as a risk factor for $A S D$

\begin{tabular}{|c|c|c|c|}
\hline \multicolumn{2}{|c|}{ Higher Maternal Age } & \multicolumn{2}{|c|}{ Higher Paternal Age } \\
\hline Higher or equal 10 years & Higher than 0 and lower 10 years & ${\text { Higher or equal } 10 \text { years }^{a}}^{a}$ & Higher than 0 and lower 10 years \\
\hline $.00[.00-\mathrm{NA}] p=.99$ & $1.97[.99,4.11] p=.06$ & $3.37[1.65,7.21] p=.001$ & $1.15[.63,2.23] p=.66$ \\
\hline
\end{tabular}


er point to be considered in this reduced of likelihood of having a child with ASD in Mexican immigrants could be the reduced level of migration that ASD individuals could have and in consequence reduce the prevalence of ASD in Mexican population residing in the United States. In contrast, in other studies exploring the immigrant status and ASD, an increase has been reported for other populations (Gillberg, Steffenburg, Börjesson, \& Andersson, 1987; Gillberg, Schaumann, \& Gillberg, 1995), but there are still no plausible hypotheses about these differences. That could be a point to be explored about what role could have, if any, the Mexican ethnicity in the estimates for ASD, and the relationship with APA.

In our analysis, we found that higher differences in parental ages increase the risks for ASD, which could be reinforcing the effect that both parents age could be playing in this relationship. In Mexico, there are only a few studies exploring the dynamics of parental conceptional ages, could prompt future studies in order to explore how this dynamic could alter the risk for ASD and correlate with other sociodemographic variables. One limitation of our study was the collection of the sample from only one city of Mexico, which could only give preliminary data about the effect of advanced paternal age as a risk factor for ASD in the Mexican population. Another limitation is that we sampled children to be in the same age range for children diagnosed with ASD and NT children. This sampling could lead to some stochastic errors in the calculation of the paternal age mean differences between cases and controls. These errors could be increased as an effect of the differences in the sample sizes of cases and controls, we have less than 200 ASD diagnosed children. The limitation in the sample size could impact the differences found in paternal age between ASD diagnosed $(M=31.54 S D \pm 8.67)$ and TD children $(M=29.17 S D \pm 8.67)$. Nevertheless, further studies in larger sample sizes are required.

Even when our results are preliminary, we point out some interesting evidence. Our analysis is the first in estimating the effect of advanced parental age in the risk for ASD in a Mexican children sample, and we found that advanced paternal age ASD could have a lower effect in the risk for ASD in our population; still, analysis on larger samples sizes are required. Also, analysis from other sources of data like epigenetic or genetic factors could help to clarify this difference.

\section{Funding}

None.

\section{Conflicts of interest}

The authors declare they have no conflicts of interest.

\section{Acknowledgements}

The authors thank all the participants of this study.

\section{REFERENCES}

Albores-Gallo, L., Roldán-Ceballos, O., Villarreal-Valdes, G., Betanzos-Cruz, B. X., Santos-Sánchez, C., Martínez-Jaime, M. M., Lemus-Espinosa, I., \& Hilton, C. L. (2012). M-CHAT Mexican Version Validity and Reliability and Some Cultural Considerations. ISRN Neurology, 2012, 1-7. doi: 10.5402/2012/408694

Baxter, A. J., Brugha, T. S., Erskine, H. E., Scheurer, R. W., Vos, T., \& Scott, J. G. (2015). The epidemiology and global burden of autism spectrum disorders. Psychological Medicine, 45(3), 601-613. doi: 10.1017/s003329171400172x

Becerra, T. A., von Ehrenstein, O. S., Heck, J. E., Olsen, J., Arah, O. A., Jeste, S. S., ... Ritz, B. (2014). Autism Spectrum Disorders and Race, Ethnicity, and Nativity: A Population-Based Study. Pediatrics, 134(1), e63-e71. doi: 10.1542/peds.2013-3928

Bilder, D., Pinborough-Zimmerman, J., Miller, J., \& McMahon, W. (2009). Prenatal, Perinatal, and Neonatal Factors Associated With Autism Spectrum Disorders. Pediatrics, 123(5), 1293-1300. doi: 10.1542/peds.2008-0927

Buizer-Voskamp, J. E., Laan, W., Staal, W. G., Hennekam, E. A. M., Aukes, M. F., Termorshuizen, F., ... Ophoff, R. A. (2011). Paternal age and psychiatric disorders: Findings from a Dutch population registry. Schizophrenia Research, 129(2-3), 128-132. doi: 10.1016/j.schres.2011.03.021

Burstyn, I., Sithole, F., \& Zwaigenbaum, L. (2010). Autism spectrum disorders, maternal characteristics and obstetric complications among singletons born in Alberta, Canada. Chronic Diseases in Canada, 30(4), 125-134.

Buwe, A., Guttenbach, M., \& Schmid, M. (2005). Effect of paternal age on the frequency of cytogenetic abnormalities in human spermatozoa. Cytogenetic and Genome Research, 111(3-4), 213-228. doi: 10.1159/000086892

Christiansz, J. A., Gray, K. M., Taffe, J., \& Tonge, B. J. (2016). Autism Spectrum Disorder in the DSM-5: Diagnostic Sensitivity and Specificity in Early Childhood. Journal of Autism and Developmental Disorders, 46(6), 2054-2063. doi: 10.1007/s10803-016-2734-4

Croen, L. A., Najjar, D. V., Fireman, B., \& Grether, J. K. (2007). Maternal and Paternal Age and Risk of Autism Spectrum Disorders. Archives of Pediatrics \& Adolescent Medicine, 161(4), 334-340. doi: 10.1001/archpedi.161.4.334

Crow, J. F. (2000). The origins, patterns and implications of human spontaneous mutation. Nature Reviews. Genetics, 1(1), 40-47. doi: 10.1038/35049558

D’Onofrio, B. M., Rickert, M. E., Frans, E., Kuja-Halkola, R., Almqvist, C., Sjölander, A., ... Lichtenstein, P. (2014). Paternal Age at Childbearing and Offspring Psychiatric and Academic Morbidity. JAMA Psychiatry, 71(4), 432438. doi: 10.1001/jamapsychiatry.2013.4525

Durkin, M. S., Maenner, M. J., Newschaffer, C. J., Lee, L., Cunniff, C. M., Daniels, J. L., Kirby, R. S., Leavitt, L., Miller, L., Zahorodny, W., \& Schieve, L. A. (2008). Advanced Parental Age and the Risk of Autism Spectrum Disorder. American Journal of Epidemiology, 168(11), 1268-1276. doi: 10.1093/aje/kwn250

Elsabbagh, M., Divan, G., Koh, Y., Kim, Y. S., Kauchali, S., Marcín, C., ... Fombonne, E. (2012). Global Prevalence of Autism and Other Pervasive Developmental Disorders. Autism Research, 5(3), 160-179. doi: 10.1002/aur.239

Flatscher-Bader, T., Foldi, C. J., Chong, S., Whitelaw, E., Moser, R. J., Burne, T. H. J., ... McGrath, J. J. (2011). Increased de novo copy number variants in the offspring of older males. Translational Psychiatry, 1(8), e34. doi: 10.1038/tp.2011.30

Fombonne, E., Marcin, C., Manero, A. C., Bruno, R., Diaz, C., Villalobos, M., ... Nealy, B. (2016). Prevalence of Autism Spectrum Disorders in Guanajuato, Mexico: The Leon survey. Journal of Autism and Developmental Disorders, 46(5), 1669-1685. doi: 10.1007/s10803-016-2696-6

Frans, E. M., Sandin, S., Reichenberg, A., Långström, N., Lichtenstein, P., McGrath, J. J., \& Hultman, C. M. (2013). Autism Risk Across GenerationsA PopulationBased Study of Advancing Grandpaternal and Paternal Age. JAMA Psychiatry, 70(5), 516-521. doi: 10.1001/jamapsychiatry.2013.1180

Gillberg, C., Schaumann, H., \& Gillberg, I. C. (1995). Autism in immigrants: children born in Sweden to mothers born in Uganda. Journal of Intellectual Disability Research, 39(2), 141-144. doi: 10.1111/j.1365-2788.1995.tb00482.x

Gillberg, C., Steffenburg, S., Börjesson, B., \& Andersson, L. (1987). Infantile Autism in Children of Immigrant Parents: A Population-based Study from Göteborg, Sweden. British Journal of Psychiatry, 150(6), 856-858. doi: 10.1192/bjp.150.6.856

Glasson, E. J., Bower, C., Petterson, B., de Klerk, N., Chaney, G., \& Hallmayer, J. F. (2004). Perinatal Factors and the Development of Autism: A Population Study. Archives of General Psychiatry, 61(6), 618-627. doi: 10.1001/archpsyc.61.6.618

Golding, J., Steer, C., \& Pembrey, M. (2010). Parental and Grandparental Ages in the Autistic Spectrum Disorders: A Birth Cohort Study. PLoS ONE, 5(4), e9939. doi: 10.1371/journal.pone.0009939 
Grether, J. K., Anderson, M. C., Croen, L. A., Smith, D., \& Windham, G. C. (2009). Risk of Autism and Increasing Maternal and Paternal Age in a Large North American Population. American Journal of Epidemiology, 170(9), 1118-1126. doi: 10.1093/aje/kwp247

Hultman, C. M., Sandin, S., Levine, S. Z., Lichtenstein, P., \& Reichenberg, A. (2011). Advancing paternal age and risk of autism: new evidence from a populationbased study and a meta-analysis of epidemiological studies. Molecular Psychiatry, 16(12), 1203-1212. doi: 10.1038/mp.2010.121

Idring, S., Magnusson, C., Lundberg, M., Ek, M., Rai, D., Svensson, A. C., ... Lee, B. K. (2014). Parental age and the risk of autism spectrum disorders: findings from a Swedish population-based cohort. International Journal of Epidemiology, 43(1), 107-115. doi: 10.1093/ije/dyt262

Janecka, M., Mill, J., Basson, M. A., Goriely, A., Spiers, H., Reichenberg, A., ... Fernandes, C. (2017). Advanced paternal age effects in neurodevelopmental disorders-review of potential underlying mechanisms. Translational Psychiatry, 7(1), e1019-e1019. doi: 10.1038/tp.2016.294

Jenkins, T. G., Aston, K. I., Pflueger, C., Cairns, B. R., \& Carrell, D. T. (2014). Age-Associated Sperm DNA Methylation Alterations: Possible Implications in Offspring Disease Susceptibility. PLoS Genetics, 10(7), e1004458. doi: 10.1371/journal.pgen. 1004458

Kent, R. G., Carrington, S. J., Le Couteur, A., Gould, J., Wing, L., Maljaars, J., ... Leekam, S. R. (2013). Diagnosing Autism Spectrum Disorder: who will get a DSM-5 diagnosis? Journal of Child Psychology and Psychiatry, 54(11), 12421250. doi: $10.1111 /$ jcpp. 12085

Kimura, R., Yoshizaki, K., \& Osumi, N. (2018). Risk of Neurodevelopmental Disease by Paternal Aging: A Possible Influence of Epigenetic Alteration in Sperm. In: Kubota, T., Fukuoka, H. (eds) Developmental Origins of Health and Disease (DOHaD). Advances in Experimental Medicine and Biology, vol 1012 (pp. 7581). Springer, Singapore. doi: 10.1007/978-981-10-5526-3_8

de Kluiver, H., Buizer-Voskamp, J. E., Dolan, C. V., \& Boomsma, D. I. (2017). Paternal age and psychiatric disorders: A review. American Journal of Medical Genetics Part B: Neuropsychiatric Genetics, 174(3), 202-213. doi: 10.1002/ajmg.b.32508

Kong, A., Frigge, M. L., Masson, G., Besenbacher, S., Sulem, P., Magnusson, G., ... Stefansson, K. (2012). Rate of de novo mutations and the importance of father's age to disease risk. Nature, 488(7412), 471-475. doi: 10.1038/nature11396

Lampi, K. M., Hinkka-Yli-Salomäki, S., Lehti, V., Helenius, H., Gissler, M., Brown, A. S., \& Sourander, A. (2013). Parental Age and Risk of Autism Spectrum Disorders in a Finnish National Birth Cohort. Journal of Autism and Developmental Disorders, 43(11), 2526-2535. doi: 10.1007/s10803-013-1801-3

Larsson, H. J., Eaton, W. W., Madsen, K. M., Vestergaard, M., Olesen, A. V., Agerbo, E., ... Mortensen, P. B. (2005). Risk Factors for Autism: Perinatal Factors, Parental Psychiatric History, and Socioeconomic Status. American Journal of Epidemiology, 161(10), 916-925. doi: 10.1093/aje/kwi123

Lauritsen, M. B., Pedersen, C. B., \& Mortensen, P. B. (2005). Effects of familial risk factors and place of birth on the risk of autism: a nationwide registerbased study. Journal of Child Psychology and Psychiatry, 46(9), 963-971. doi: 10.1111/j.1469-7610.2004.00391.x

Lee, P. F., Thomas, R. E., \& Lee, P. A. (2015). Approach to autism spectrum disorder: Using the new DSM-V diagnostic criteria and the CanMEDS-FM framework. Canadian Family Physician, 61(5), 421-424.

Liptak, G. S., Benzoni, L. B., Mruzek, D. W., Nolan, K. W., Thingvoll, M. A., Wade, C. M., \& Fryer, G. E. (2008). Disparities in Diagnosis and Access to Health Services for Children with Autism: Data from the National Survey of Children's Health. Journal of Developmental \& Behavioral Pediatrics, 29(3), 152-160. doi: $10.1097 / \mathrm{dbp} .0 \mathrm{~b} 013 \mathrm{e} 318165 \mathrm{c} 7 \mathrm{a} 0$

Lord, C., Rutter, M., \& Le Couteur, A. (1994). Autism Diagnostic Interview-Revised: A revised version of a diagnostic interview for caregivers of individuals with possible pervasive developmental disorders. Journal of Autism and Developmental Disorders, 24(5), 659-685. doi: 10.1007/bf02172145

Lundstrom, S., Haworth, C. M. A., Carlstrom, E., Gillberg, C., Mill, J., Rastam, M., ... Reichenberg, A. (2010). Trajectories leading to autism spectrum disorders are affected by paternal age: findings from two nationally representative twin studies. Journal of Child Psychology and Psychiatry, 51(7), 850-856. doi: 10.1111/j.1469-7610.2010.02223.x

Maimburg, R. D., \& Vaeth, M. (2006). Perinatal risk factors and infantile autism. Acta Psychiatrica Scandinavica, 114(4), 257-264. doi: 10.1111/j.16000447.2006.00805.x

Mamidala, M. P., Polinedi, A., P T V, P. K., Rajesh, N., Vallamkonda, O. R., Udani, V., ...
Rajesh, V. (2013). Prenatal, perinatal and neonatal risk factors of Autism Spectrum Disorder: A comprehensive epidemiological assessment from India. Research in Developmental Disabilities, 34(9), 3004-3013. doi: 10.1016/j.ridd.2013.06.019

Muhle, R. A., Reed, H. E., Stratigos, K. A., \& Veenstra-VanderWeele, J. (2018). The Emerging Clinical Neuroscience of Autism Spectrum Disorder. A review. JAMA Psychiatry, 75(5), 514-523. doi: 10.1001/jamapsychiatry.2017.4685

Parner, E. T., Baron-Cohen, S., Lauritsen, M. B., Jørgensen, M., Schieve, L. A., Yeargin-Allsopp, M., \& Obel, C. (2012). Parental Age and Autism Spectrum Disorders. Annals of Epidemiology, 22(3), 143-150. doi: 10.1016/j. annepidem.2011.12.006

Pedersen, A., Pettygrove, S., Meaney, F. J., Mancilla, K., Gotschall, K., Kessler, D. B., ... Cunniff, C. (2012). Prevalence of autism spectrum disorders in Hispanic and non-Hispanic white children. Pediatrics, 129(3), e629-e635. doi: 10.1542/ peds.2011-1145

Pinborough-Zimmerman, J., Bilder, D., Bakian, A., Satterfield, R., Carbone, P. S., Nangle, B. E., ... McMahon, W. M. (2011). Sociodemographic risk factors associated with autism spectrum disorders and intellectual disability. Autism Research, 4(6), 438-448. doi: 10.1002/aur.224

Reichenberg, A., Gross, R., Sandin, S., \& Susser, E. S. (2010). Advancing paternal and maternal age are both important for autism risk. American Journal of Public Health, 100(5), 772-773. doi: 10.2105/ajph.2009.187708

Sanders, S., Ercan-Sencicek, A., Hus, V., Luo, R., Murtha, M., Moreno-De-Luca, D., ... State, M. (2011). Multiple Recurrent De Novo CNVs, Including Duplications of the 7q11.23 Williams Syndrome Region, Are Strongly Associated with Autism. Neuron, 70(5), 863-885. doi: 10.1016/j.neuron.2011.05.002

Sandin, S., Schendel, D., Magnusson, P., Hultman, C., Surén, P., Susser, E., ... Reichenberg, A. (2016). Autism risk associated with parental age and with increasing difference in age between the parents. Molecular Psychiatry, 21(5), 693-700. doi: 10.1038/mp.2015.70

Sasanfar, R., Haddad, S. A., Tolouei, A., Ghadami, M., Yu, D., \& Santangelo, S. L. (2010). Paternal age increases the risk for autism in an Iranian population sample. Molecular Autism, 1(1), 2. doi: 10.1186/2040-2392-1-2

Schieve, L. A., Boulet, S. L., Blumberg, S. J., Kogan, M. D., Yeargin-Allsopp, M., Boyle, C. A., ... Rice, C (2012). Association between parental nativity and autism spectrum disorder among US-born non-Hispanic white and Hispanic children, 2007 National Survey of Children's Health. Disability and Health Journal, 5(1), 18-25. doi: 10.1016/j.dhjo.2011.09.001

Shelton, J. F., Tancredi, D. J., \& Hertz-Picciotto, I. (2010). Independent and dependent contributions of advanced maternal and paternal ages to autism risk. Autism Research, 3(1), 30-39. doi: 10.1002/aur.116

Siu, A. L., Bibbins-Domingo, K., Grossman, D. C., Baumann, L. C., Davidson, K. W., Ebell, M., ... Pignone, M. P. (2016). Screening for Autism Spectrum Disorder in Young Children. US Preventive Services Task Force Recommendation Statement. JAMA, 315(7), 691-696. doi: 10.1001/jama.2016.0018

Sun, X., Allison, C., Auyeung, B., Baron-Cohen, S., \& Brayne, C. (2014). Parental concerns, socioeconomic status, and the risk of autism spectrum conditions in a population-based study. Research in Developmental Disabilities, 35(12), 3678 3688. doi: 10.1016/j.ridd.2014.07.037

Szatmari, P., Paterson, A. D., Zwaigenbaum, L., Roberts, W., Brian, J., Liu, X., ... Shih, A. (2007). Mapping autism risk loci using genetic linkage and chromosomal rearrangements. Nature Genetics, 39(3), 319-328. doi: 10.1038/ng1985

The R Development Core Team. (2008). R: A language and environment for statistical computing. R Development Core Team. Version 2.6 .2 (2008-02-08). R Foundation for Statistical Computing.

van Balkom, I. D. C., Bresnahan, M., Vuijk, P. J., Hubert, J., Susser, E., \& Hoek, H. W. (2012). Paternal Age and Risk of Autism in an Ethnically Diverse, NonIndustrialized Setting: Aruba. PLoS ONE, 7(9), e45090. doi: 10.1371/journal. pone. 0045090

Williams, K., Helmer, M., Duncan, G. W., Peat, J. K., \& Mellis, C. M. (2008). Perinatal and maternal risk factors for autism spectrum disorders in New South Wales, Australia. Child: Care, Health and Development, 34(2), 249-256. doi: 10.1111/j.1365-2214.2007.00796.x

Wu, S., Wu, F., Ding, Y., Hou, J., Bi, J., \& Zhang, Z. (2017). Advanced parental age and autism risk in children: a systematic review and meta-analysis. Acta Psychiatrica Scandinavica, 135(1), 29-41. doi: 10.1111/acps.12666

Zhang, X., Lv, C., Tian, J., Miao, R., Xi, W., Hertz-Picciotto, I., \& Qi, L. (2010). Prenatal and Perinatal Risk Factors for Autism in China. Journal of Autism and Developmental Disorders, 40(11), 1311-1321. doi: 10.1007/s10803-010-0992-0 